\title{
O critério inter-americano sobre anistias: absolutismo de direitos humanos?**
}

\section{The inter-american view on amnesties: Human rights absolutism?}

ÍNDICE

Introdução. I. Justiça transicional e a dimensão de contestação dos processos de transformação política. II. Critério interamericano sobre anistias: uma visão crítica. Considerações finais. Referências bibliográficas.

RESUMO

O objetivo deste estudo é debater a argumentação desenvolvida pela Corte Interamericana de Direitos Humanos relativamente a processos de transição política na América Latina. Em sua jurisprudência sobre o tema, a corte determinou a incompatibilidade entre legislações de anistias domésticas e os dispositivos da Convenção Americana de Direitos Humanos. Sem buscar definir a natureza ou o conteúdo de uma possível obrigação internacional de julgar violações de direitos humanos, este estudo analisa o posicionamento da corte enquanto resultado de uma atividade interpretativa; um discurso que reflete uma posição particular do órgão, mas que é apresentado como algo universal. Diversamente do entendimento da corte, o argumento central deste trabalho consiste em afir-

* Professora e coordenadora do Curso de Relações Internacionais da Universidade Federal de São Paulo (UNIFESP), Brasil. Doutora (2012) e mestre (2006) em Direito Internacional pela Universidade de São Paulo (USP), Brasil. Correio eletrônico: fabia.vecoso@ unifesp.br

Assistant Professor of International Relations, Federal University of São Paulo (UNIFESP), Brazil. Ph.D. (2012) and LL.M. (2006) in International Law, State University of São Paulo (USP), Brazil. Electronic address: fabia.vecoso@unifesp.br

Os argumentos deste artigo se baseiam em minha tese de doutorado, em que analisei e discuti a jurisprudência da CIDH sobre anistias. Ver FABIA F. CARVALHO VEÇOSO. Entre absolutismo de direitos humanos e história contextual: aspectos da experiência da Corte Interamericana de Direitos Humanos. 2012. Tese (Doutorado em Direito) - Faculdade de Direito, Universidade de São Paulo, São Paulo, 2012.

Neste texto, todas as traduções de textos em língua estrangeira para o Português foram feitas pela autora, salvo onde indicado de forma diversa.

** Recibido el: 30 de julio de 2015, aprobado el: 12 de octubre de 2015.

Para citar el artículo: F. Fernandes CARVAlHo V., O critério inter-americano sobre anistias: absolutismo de direitos humanos?, Derecho del Estado n..$^{\circ} 35$, Universidad Externado de Colombia, julio-diciembre de 2015, pp. 3-26. DOI: http://dx.doi.org/10.18601/01229893.n35.01 
mar que, em contextos envolvendo mudança de regime e violações de direitos, tanto anistias quanto julgamentos podem ser alternativas justificadas com base em uma perspectiva de direitos humanos. Nesse sentido, não seria possível apontar em abstrato uma ou outra alternativa como a mais adequada, sob pena de adoção de uma preferência ideológica. Em virtude da indeterminação do discurso de direitos humanos, diversas soluções jurídicas podem ser articuladas com o objetivo de promover uma transição política pacífica e a opção pela melhor estratégia só pode ser alcançada contextualmente.

\section{PALAVRAS-CHAVE}

Corte Interamericana de Direitos Humanos. Anistia. Transição política. América Latina.

\section{ABSTRACT}

This study aims at debating the Inter-American Court of Human Rights' reasoning regarding transitional processes in Latin America. In its case law on the topic, the court has determined that national amnesty laws lack legal effects. With no intention to define the nature or content of a duty to punish in international law, this study analyzes the court's reasoning as a result of an interpretive activity, a discourse that reflects a particular position of the organ, but is presented as something universal. Differently from the court's approach, the main argument discussed herein is that amnesties and trials can both be justified from a human rights perspective in contexts of regime change and human rights violations. In this setting, it is not possible to indicate a priori one alternative or another as the adequate one without showing an ideological preference. In view of the idea of the indeterminacy of rights, different legal solutions can be articulated to promote a peaceful political transition, and the relative usefulness of one solution can only be determined contextually.

\section{KEYWORDS}

Inter-American Court of Human Rights. Amnesty. Political Transition. Latin America.

7. For the purposes of this study, an amnesty is considered to be the juridical expression of a political act whose expected effects directly concern the promotion or protection of human rights and, in some instances, the return to, or consolidation of, democracy: 
Because the amnesty encourages national consensus in the wake of a political change brought about in a democratic framework (elections...);

Because it is the first act in the initiation of a democratic process or marks a return to democracy; or Because it is intended to block an internal crisis (non-international armed conflict) or to mark the end of an international armed conflict. Study of amnesty laws and their role in the safeguard and promotion of human rights, Relatório preliminar de Louis Joinet, relator especial, 21 de Junho de 1985, p. $4^{[1]}$.

\section{INTRODUÇÃO}

O trecho acima citado foi retirado do relatório elaborado por Louis Joinet em 1985 sobre anistias e proteção a direitos humanos. Esse estudo compreendeu uma sistematização de práticas estatais relacionadas à adoção de leis de anistia em mais de 80 países, com o objetivo de oferecer parâmetros de referência para autoridades que busquem iniciar processos de anistia, assim como para juristas responsáveis pela elaboração de leis de anistia ${ }^{2}$.

Segundo o relatório de 1985, o primeiro estudo comparado sobre anistias ${ }^{3}$, essas podem ser entendidas como instrumento capaz de promover a proteção de direitos humanos em situações concretas de conflito na medida em que podem facilitar a instauração ou a consolidação de um processo democrático, encorajando o consenso nacional na esteira da mudança política, além de possibilitar o término de conflitos nacionais e internacionais.

No entanto, desde 1985, essa visão sobre anistias como instrumento para a proteção de direitos humanos em processos de mudança de regime e

1 Comissão de Direitos Humanos das Nações Unidas, Subcomissão para Prevenção de Discriminação e Proteção de Minorias. The administration of justice and the human rights of detainees. Question of the Human Rights of Persons Subjected to Any Form of Detention or Imprisonment. Study on amnesty laws and their role in the safeguard and promotion of human rights. Preliminary report by Mr. LouIS JOINET, Special Rapporteur (1985). Document E/CN.4/ Sub.2/1985/16/Rev.1., 21 jun. 1985. Disponível em: <http://www1 umn.edu/humanrts/Amensty\%20Laws_Joinet.pdf>. Acesso em: 28 jul. 2015.

2 Comissão de Direitos Humanos das Nações Unidas, Subcomissão para Prevenção de Discriminação e Proteção de Minorias. The administration, p. 22.

3 Louise Mallinder. "Perspectivas transnacionais sobre anistias", em Leigh A. PAYNe, Paulo Abrã̃o, Marcelo D. Torelly (Orgs.). A anistia na era da responsabilização: o Brasil em perspectiva internacional e comparada, Brasília, Ministério da Justiça, Comissão de Anistia e Oxford, Oxford University Press, Latin American Centre, 2011, p. 477. 
transformação política tem sofrido intensa transformação. $\mathrm{O}$ contexto atual da chamada luta contra impunidade em direito internacional (fight against impunity) apresenta um entendimento oposto: anistias devem ser evitadas em processos transicionais na medida em que favorecem a impunidade de perpetradores de direitos humanos, desrespeitando os direitos das vítimas de violações. Em recente publicação intitulada Amnesty in the age of Human Rights Accountability, Leigh A. Payne e Francesca Lessa descrevem esse cenário atual de uma "era da responsabilização":

This age of accountability has meant that amnesty laws around the world have faced challenges from domestic, regional, and international courts, as well as from mobilized local and international victims, survivors, and human rights organizations. This tremendous and unprecedented global progress suggests that we now live in an age of accountability in which governments and international institutions are expected to hold perpetrators of atrocities legally responsible for their acts ${ }^{4}$.

A Corte Interamericana de Direitos Humanos (CIDH ou corte) tem tido intensa participação na conformação de um standard internacional direcionado a afirmar a obrigação de punir violações de direitos humanos. Em uma série de cinco casos julgados pela corte em face do $\mathrm{Peru}^{5}, \mathrm{Chile}^{6}, \mathrm{Brasil}^{7}$, Uruguai ${ }^{8}$ e,

4 Leigh A. Payne e Francesca Lessa. "Introduction", em Leigh A. Payne e FrancesCA LESSA (eds.). Amnesty in the age of Human Rights Accountability, Cambridge, Cambridge University Press, 2012, p. 43. Para mais argumentos a respeito do surgimento de uma "era da responsabilização", ver nesse mesmo volume KATHRYN SiKKINK. "The Age of Accountability: the global rise of individual criminal accountability", em LEIGH A. PAYNE e FRANCESCA LESSA (eds.). Amnesty in the age of Human Rights Accountability, Cambridge, Cambridge University Press, 2012, p. 63-88.

5 Corte Interamericana de Direitos Humanos. Caso Barrios Altos Vs. Peru. Mérito. 14 mar. 2001a. Série C n. ${ }^{\circ}$ 75. Disponível em: <http://www.corteidh.or.cr/casos.cfm>. Acesso em: 28 jul. 2015; Corte Interamericana de Direitos Humanos. Caso Barrios Altos Vs. Peru. Interpretação da sentença de mérito. 3 set. 2001b. Série C n. ${ }^{\circ}$ 83. Disponível em: <http://www.corteidh.or.cr/ casos.cfm>. Acesso em: 28 jul. 2015; Corte Interamericana de Direitos Humanos. Caso Barrios Altos vs. Peru. Reparações e custas. 30 nov. 2001c. Série C n. ${ }^{\circ} 87$. Disponível em: <http://www. corteidh.or.cr/casos.cfm>. Acesso em: 28 jul. 2015.

6 Corte Interamericana de Direitos Humanos. Caso Almonacid-Arellano et al.vs. Chile. Exceções preliminares, mérito, reparações e custas, 26 set. 2006a. Série C n. ${ }^{\circ} 154$. Disponível em: <http://www.corteidh.or.cr/casos.cfm>. Acesso em: 28 jul. 2015.

7 Corte Interamericana de Direitos Humanos. Caso Gomes Lund et al. (Guerrilha do Araguaia) vs. Brasil. Exceções preliminares, mérito, reparações e custas. 24 nov. 2010. Série C n. ${ }^{0}$ 219. Disponível em: <http://www.corteidh.or.cr/casos.cfm>. Acesso em: 28 jul. 2015.

8 Corte Interamericana de Direitos Humanos. Caso Gelman vs. Uruguai. Mérito e reparações. 24 fev. 2011. Série C n. ${ }^{\circ} 221$. Disponível em: <http://www.corteidh.or.cr/casos.cfm>. Acesso em: 28 jul. 2015. 
mais recentemente, El Salvador ${ }^{9}$, a CIDH tem afirmado a ilicitude de anistias internas perante a Convenção Americana de Direitos Humanos (convenção ou Pacto de San José da Costa Rica) e mesmo perante o direito internacional.

Segundo a corte, as leis de anistia adotadas no âmbito dos processos transicionais peruano, chileno, brasileiro, uruguaio e salvadorenho são incompatíveis com os direitos previstos no Pacto de San José da Costa Rica, na medida em que anistias nacionais necessariamente impediriam a investigação e o julgamento de graves violações de direitos humanos, promovendo a impunidade. As vítimas e os familiares das vítimas ficariam impedidos de conhecer a verdade a respeito dos fatos, sendo-lhes vedado qualquer tipo de reparação ante as violações perpetradas. A corte afirma, ainda, o caráter inderrogável das normas de direitos humanos violadas no decorrer de regimes autoritários na América Latina, eis que tortura, desaparecimentos forçados, execuções arbitrárias, por exemplo, seriam todas violações a normas imperativas de direito internacional. Nesse contexto de graves violações de direitos humanos, não pode ser permitiria a concessão do benefício da anistia, sendo afirmada a obrigação dos Estados-partes na convenção de investigar os fatos, julgar e eventualmente punir os responsáveis pelas violações. Essa série de casos tem sido referida como o "critério interamericano sobre anistias"

Esta contribuição possui como objeto a construção argumentativa da corte a respeito de anistias e processos de mudança de regime na América Latina. Sem buscar definir a natureza ou o conteúdo de uma possível obrigação internacional de julgar violações de direitos humanos, este estudo analisa o posicionamento da corte enquanto resultado de uma atividade interpretativa; um discurso que reflete uma posição particular do órgão, mas que é

9 Corte Interamericana de Direitos Humanos. Caso Massacres de El Mozote e lugares adjacentes vs. El Salvador. Mérito, Reparações e Custas. 25 out. 2012. Série C n. ${ }^{\circ} 252$. Disponível em: <http://www.corteidh.or.cr/casos.cfm>. Acesso em: 28 jul. 2015.

10 O caso La Cantuta, decidido pela CIDH em face do Peru após o caso Barrios Altos, consolidou a expressão "critério interamericano sobre anistias". Nos termos do voto fundamentado do juiz Sergio García Ramírez, voto adicionado à decisão de mérito no caso La Cantuta: "En síntesis, el criterio de la Corte Interamericana en esta materia plantea: a) la vigencia de los deberes de respeto y garantía establecidos en el artículo 1 de la Convención Americana de Derechos Humanos (CADH), no obstante los obstáculos de derecho interno que pudieran desencaminar el debido cumplimiento de esas obligaciones asumidas por el Estado, en ejercicio de su soberanía, al constituirse como parte en la Convención; b) el consecuente destierro de la impunidad por delitos de suma gravedad -violaciones graves a los derechos humanos-que pudiera provenir de esos obstáculos; y c) el deber del Estado de introducir en su orden interno las medidas necesarias para alcanzar la vigencia de aquellos deberes y el destierro de esa impunidad, conforme a lo estipulado en el artículo 2 CADH". Corte Interamericana de Direitos Humanos. Caso La Cantuta vs. Peru. Mérito, reparações e custas. 29 nov. 2006b. Série C n. ${ }^{\circ} 162$. Voto Fundamentado Ramírez, par. 3. Disponível em: <http://www.corteidh.or.cr/casos.cfm>. Acesso em: 28 jul. 2015. 
apresentado como algo universal. Diversamente do entendimento da corte, o argumento central deste trabalho consiste em afirmar que, em contextos envolvendo mudança de regime e violações de direitos, tanto anistias quanto julgamentos podem ser alternativas justificadas com base em uma perspectiva de direitos humanos. Nesse sentido, não seria possível apontar em abstrato uma ou outra alternativa como a mais adequada, sob pena de adoção de uma preferência ideológica.

Para tanto, este artigo divide-se em duas partes. A próxima seção de texto apresentará o entendimento de justiça de transição que será utilizado neste estudo, perspectiva teórica fundamental para analisar a construção argumentativa da corte sobre anistias. Após, será analisado de forma crítica o "critério interamericano sobre anistias". O artigo se encerra com considerações a respeito de um discurso absolutista de direitos humanos articulado pela CIDH.

\section{JUSTIÇA TRANSICIONAL E A DIMENSÃO DE CONTESTAÇÃO DOS PROCESSOS DE TRANSFORMAÇÃO POLÍTICA}

Sociedades que experimentaram conflitos envolvendo guerras civis, governos repressores e/ou violações generalizadas de direitos humanos enfrentaram, em alguma medida, questões relacionadas ao término do conflito e ao restabelecimento de relações pacíficas em face do legado do regime político anterior.

A chamada justiça de transição se ocupa da concepção de justiça associada a períodos de mudança política, em que são discutidas as alternativas jurídicas aplicáveis às transgressões empreendidas pelo regime anterior ${ }^{11}$.

Nesse sentido, há uma relação estreita entre a política e o direito em um cenário radical de alteração de regime, de forma que as soluções jurídicas pensadas para concretizar o momento de transição possuem um papel importante na constituição do novo regime. Em momentos extraordinários de mudança política, a função do direito é fortemente paradoxal: ao mesmo tempo em que deve restabelecer a ordem e a estabilidade - sua função em situações ordinárias -, também deve possibilitar a transformação política, com a constituição de um regime diverso do visto no passado. Ao mesmo tempo em que a concepção de justiça constitui a transição política, essa concepção também é constituída pela transiçãa ${ }^{12}$.

Assim, a concepção de justiça relacionada a períodos de mudança política seria diversa da concepção vigente em momentos em que não são vivenciadas tais transformações. O que é considerado justo depende de uma vivência an-

11 Ruti Teitel. Transitional justice genealogy, Harvard Human Rights Journal, Cambridge, v. 16, 2003, p. 69.

12 Ruti Teitel. Transitional justice, New York, Oxford University Press, 2000, p. 4-6. 
terior tida como injusta, de forma que a concepção de justiça em momentos de transição política seria parcial e contingente ${ }^{13}$.

Em processos de mudança política, diversas questões se apresentam para debate e para decisão. Os dilemas de justiça transicional podem ser apresentados nos seguintes termos: como demarcar claramente a divisão entre o velho e o novo regime? Para a superação da situação de conflito, haveria uma medida adequada entre uma ação ostensiva de "caça às bruxas" e um total esquecimento do passado? O que fazer com os líderes do regime anterior, com as pessoas que trabalharam como funcionários públicos e com eventuais colaboradores informais? Todos devem ser processados judicialmente? Ou somente os líderes do antigo regime? Deve-se purgar o novo regime dos antigos funcionários públicos? Seria possível alcançar um consenso sobre quem seria vítima e quem seria algoz em regimes que afetaram sociedades como um todo? Se a última pergunta puder ser respondida de maneira afirmativa, devem-se reparar as vítimas? Qual seria a medida adequada de reparação, considerando não só a situação das vítimas, mas também a questão mais ampla de alocação de recursos materiais para constituição do novo regime? De uma forma geral, como lidar com os custos desse processo de mudança política? Seria possível obter reconciliação nacional nesse processo, com o objetivo de prevenir a ocorrência de novas violações de direitos humanos? Como re-

13 TeITEL. Transitional justice, cit., p. 6. Para uma visão diversa, negando o caráter especial da concepção de justiça em momentos de transição política, ver ERIC A. POSNER, ADRIAN VERMUELE. Transitional justice as ordinary justice, Harvard Law Review, Cambridge, v. 117, n. ${ }^{\circ}$ 3 , p. 761-825, 2004. THOMAS CAROTHERS critica fortemente a perspectiva de justiça tida como excepcional em momentos de mudança de regime, afirmando que aquilo que é considerado como extraordinário ou precário seria, na realidade, a situação de normalidade para muitos Estados, incluindo países em desenvolvimento e países que deixaram o regime comunista. Cf. THOMAS CAROTHERS. The end of the transition paradigm, Journal of Democracy, Washington, v. 13. n. ${ }^{\circ}$ 1,2002, p. 18. O debate sobre o que pode ser considerado normal ou excepcional em termos de justiça de transição foi abordado por RUTI TEITEL, sendo afirmado pela autora um movimento de normalização ou globalização desse campo de estudos no momento atual. TEITEL explica que essa fase da justiça de transição seria caracterizada por um movimento que parece deixar de lado o caráter excepcional das respostas encontradas em momentos de transição política para uma condição invariável de justiça transicional (steady-state transitional justice), relacionada a fenômenos pós-conflito que emergem de situações das mais diversas, incluindo conflitos étnicos e guerras civis, com a correspondente expansão do uso do direito internacional humanitário. Cf. Ruti Teitel. Editorial note: transitional justice globalized. The International Journal of Transitional Justice, Oxford, v. 2, n. ${ }^{\circ}$ 1, p. 1-4, 2008. Não constitui objeto do presente trabalho debater as transformações relacionadas ao campo da justiça de transição. De forma breve, e considerando as observações mencionadas nesta nota, a jurisprudência da corte debatida neste estudo não parece estar relacionada à chamada fase globalizada de justiça transicional, mas a situações excepcionais de mudança de regime político na América Latina, o que justifica a posição adotada no presente trabalho relativamente ao caráter especial da concepção de justiça em momentos de transformação política. 
conhecer o passado em termos históricos, em meio a narrativas concorrentes sobre as ações do antigo regime? Seria possível alcançar a verdade sobre tais fatos? Quem seria a voz portadora dessa verdade? ${ }^{14}$.

Diferentes objetivos podem ser identificados com base nas questões listadas acima, tais como a responsabilização dos integrantes do regime anterior pelos atos do passado (accountability), a prevenção de novos conflitos, a implementação dos direitos das vítimas, a pacificação social, a reconciliação nacional, a construção da verdade sobre o passado, entre outros.

Em situações concretas, como as que foram objeto de análise pela $\mathrm{CIDH}$, esses objetivos podem se apresentar em tensão entre si por força do mencionado paradoxo relacionado à justiça de transição - ao mesmo tempo em que é preciso restabelecer a ordem e fazer cessar a situação de conflito, mecanismos de justiça de transição devem possibilitar a transformação política, legitimando a criação de um novo regime ${ }^{15}$.

O que se quer salientar é a dimensão de contestação envolvida em processos de transição política. Muitas questões estão abertas para reflexão e debate e as escolhas empreendidas durante o processo de transição podem ter consequências variadas, as quais também se relacionam com as estratégias adotadas para transformação do antigo regime.

Não há garantias de que todas as dificuldades serão enfrentadas e superadas, tendo em vista a ampla gama de interesses que se apresenta em processos de alteração de regime, articulados por grupos dos mais diversos. Faz-se necessário, assim, atentar para as referidas complexidades dos processos de transformação política, em que a concretização de determinados objetivos pode deixar outras questões obscurecidas ${ }^{16}$.

Essas observações a respeito do campo da justiça transicional são relevantes para o presente trabalho, posto que o seu objetivo é apresentar uma visão crítica a respeito da jurisprudência da CIDH.

A decisão pela concessão de anistia ou pela realização de julgamentos de responsáveis por violações de direitos humanos, questões debatidas neste estudo, envolve também a discussão a respeito do que é considerado relevante em determinado caso concreto de transição, o que depende dos objetivos e do contexto de cada processo de alteração de regime. Como ilustram os questionamentos apresentados acima, verificam-se fortes embates políticos a respeito

14 NeIL J. KRITZ "The dilemmas of transitional justice", em NeIL J. KRITZ (ed.). Transitional justice: How emerging democracies reckon with former regimes, Washington, United States Institute of Peace, 1995, v. 1, p. xix-xx.

15 BRonwyn AnNe LEEBAw. The irreconcilable goals of transitional justice, Human Rights Quarterlys Baltimore, v. 33, n. ${ }^{\circ}$ 1, 2008, p. 97.

16 LeEBaw. The irreconcilable, cit., p. 118. 
de quais deveriam ser os objetivos de processos transicionais. A adoção de mecanismos de justiça de transição está, assim, intimamente relacionada a batalhas e escolhas políticas ${ }^{17}$.

Não se busca apresentar aqui a definição da melhor resposta jurídico-institucional sobre transição política, mas apenas lançar luz sobre a importância de compreender o que está em jogo em processos de mudança de regime. Deve-se ressaltar que o campo da justiça transicional, tal como se apresenta atualmente, tampouco seria capaz de apresentar a priori a melhor saída em termos de transição política. Adota-se aqui o entendimento discutido por Christine Bell ${ }^{18}$, segundo o qual transição seria algo diverso de uma situação pós-conflito. A atuação da justiça de transição compreende a esperança de lidar com situações conflituosas de maneira menos violenta em comparação com o verificado no passado, buscando-se traduzir a violência do conflito em um conjunto de estruturas institucionais políticas e jurídicas capazes de permitir que as mesmas batalhas políticas relacionadas à situação conflituosa do passado possam ocorrer, mas de forma menos violenta, possibilitando o estabelecimento de novos acordos políticos.

Não há qualquer garantia de que a mera adoção dos chamados mecanismos de justiça de transição - como anistias, comissões de verdade, julgamentos, programas de reparação, dentre outros - possa resolver e encerrar os conflitos políticos relacionados ao regime anterior. A problemática da justiça de transição não se reduz a um conjunto de alternativas técnicas, como se houvesse uma caixa de ferramentas disponível para consertar situações conflituosas - o próprio uso do termo "mecanismo" parece contribuir para esse entendimento ${ }^{19}$. Para além de considerar o direito e as estratégias jurídicas de justiça de transição, é preciso levar em conta uma dimensão de discordância, de contestação, ou de embate relacionada a contextos de transformação política. Desconsiderar essa dimensão enseja uma simplificação demasiada de um passado marcado por violência.

\section{CRITÉRIO INTERAMERICANO SOBRE ANISTIAS: UMA VISÃO CRÍTICA}

Para um debate sobre a argumentação desenvolvida pela CIDH sobre anistias, algumas questões devem ser esclarecidas. Primeiramente, vale ressaltar que anistias têm sido adotadas pelos Estados de forma crescente desde o final da

17 Ruti TeITEL. Editorial note, cit., p. 2.

18 Christine Bell. Transitional justice, interdisciplinarity and the state of the 'field' or 'non-field', The International Journal of Transitional Justice, Oxford, v. 3, n. ${ }^{\circ}$ 1, p. 25, 2009.

19 Christine Bell. Transitional justice, cit., p. 27. 
Segunda Guerra Mundial ${ }^{20}$. Em comparação com outras alternativas jurídicas disponíveis para enfrentar situações de violação de direitos humanos e contextos de transição política, como comissões de verdade, julgamentos, programas de reparação e lustração, anistias têm se apresentado como mecanismo preponderante na prática estatal ${ }^{21}$.

Em segundo lugar, o dever estatal de julgar violações de direitos humanos é estabelecido de forma expressa em alguns tratados internacionais que versam sobre violações específicas de direitos humanos ${ }^{22}$. Tal obrigação está presente na Convenção para a Prevenção e Repressão do Crime de Genocídio, em seu artigo $6^{\circ}$; na Convenção Internacional sobre a Eliminação de Todas as Formas de Discriminação Racial, em seu artigo $6^{\circ}$; na Convenção contra a Tortura e outros tratamentos ou penas cruéis, desumanos ou degradantes, em seu artigo $7^{\circ} \mathrm{e}$, mais recentemente, na Convenção Internacional para Proteção de Todas as Pessoas contra o Desaparecimento Forçado, em seu artigo $7^{\circ[23]}$.

Para além desses tratados, deve-se mencionar que as Convenções de Genebra de 1949, sobre o tratamento de prisioneiros de guerra e de civis em territórios ocupados, também estabelecem expressamente a obrigação de julgar os responsáveis por graves violações às obrigações previstas nas referidas convenções ${ }^{24}$.

A Convenção Americana de Direitos Humanos não estabelece, de forma expressa, um dever dos Estados-partes de julgar violações. $\mathrm{O}$ artigo $1^{\circ}$ da convenção estabelece uma obrigação de caráter geral, assumida pelos Estados no momento da adesão ao sistema interamericano: garantir o respeito aos direitos previstos na Convenção Americana ${ }^{25}$. Outros tratados gerais de

20 LOUISE MALLINDER. Amnesty, human rights and political transitions: Bridging the peace and justice divide, Oxford, Hart Publishing, 2008, p. 19.

21 Tricia D. Olsen, Leigh A. Payne, Andrew G. Reiter. Transitional justice in balance: comparing processes, weighing efficacy, Washington, United States Institute of Peace, 2010, p. 39.

22 Anja SeIBert-Fohr. Prosecuting serious human rights violations, Oxford, Oxford University Press, 2009, p. 8.

23 Tratados disponíveis na íntegra na página do Alto-Comissariado das Nações Unidas para Direitos Humanos. Disponível em: <http://acnudh.org/pt-br/biblioteca-virtual-pt/instrumentosuniversais/>. Acesso em: 28 jul. 2015.

24 Convenção I, sobre a situação de feridos e doentes de forças armadas terrestres, conforme artigos 49 e 50; Convenção II, sobre a situação de feridos, doentes e náufragos de forças armadas marítimas, artigos 50 e 51; Convenção III, sobre prisioneiros de guerra, artigos 129 e 130 e Convenção IV, sobre proteção de civis em tempos de guerra, artigos 146 e 147. Tratados disponíveis na íntegra em: <https://www.icrc.org/pt/guerra-e-o-direito/tratados-e-direito-consuetudinario/ convencoes-de-genebra $>$. Acesso em: 28 jul. 2015.

25 Convenção Americana de Direitos Humanos disponível em: <http://www.cidh.oas.org/ basicos/portugues/c.convencao_americana.htm>. Acesso em: 28 jul. 2015. 
direitos humanos, como o Pacto Internacional de Direito Civis e Políticos das Nações Unidas e a Convenção Europeia de Direitos do Homem, também não estabelecem expressamente um dever de julgar violações ${ }^{26}$.

Tem-se, assim, que a argumentação desenvolvida pela Corte Interamericana afirmando a incompatibilidade das anistias latino-americanas em relação a um dever estatal de julgar violações de direitos humanos não se constitui em uma posição objetivamente definida em direito internacional. A recorrente adoção de anistias pelos Estados pode colocar em xeque a existência de uma obrigação internacional de caráter costumeiro estabelecendo um dever de julgamento, e a variedade das disposições de tratados de direitos humanos também abre possibilidade para esse questionamento ${ }^{27}$.

Para além de almejar definir a natureza ou o conteúdo de uma possível obrigação internacional de julgar violações de direitos humanos, o que está em jogo aqui é lidar com o posicionamento da corte enquanto resultado de uma atividade interpretativa que favorece uma determinada maneira de lidar com contextos de mudança de regime e violações de direitos humanos, enquanto discurso que reflete uma posição particular do órgão, mas que é apresentado como algo universal; um entendimento afirmado como naturalmente superior em relação às saídas encontradas pelos Estados para concretizar a transformação política.

Assim, não constitui objetivo deste trabalho debater um modelo ideal de funcionamento da Corte Interamericana ou apontar diretrizes que busquem, eventualmente, "corrigir" a atuação do órgão. De maneira mais restrita, considera-se argumentação da corte nos casos que envolveram anistias latino-americanas e as escolhas políticas subjacentes a essa argumentação, levando em conta que o discurso da corte sobre esse tema não constitui manifestação neutra, mas posicionamento que é defendido com base em determinadas escolhas.

O caso Barrios Altos estabeleceu-se como precedente da corte em matéria de anistias domésticas. As afirmações que foram elaboradas sobre anistias nesse caso foram reproduzidas pela corte nos julgados subsequentes, até o caso mais recente El Mozote, decidido em 2012. Nas palavras da corte no caso peruano:

26 DiAnE F. Orentlicher Settling accounts: the duty to prosecute human rights violations of a prior regime, Yale Law Journal, New Haven, v. 100, n. . 8, 1990-1991, p. 2568.

27 Para uma discussão aprofundada sobre anistias como violações ao direito internacional, isto é, para um debate de caráter mais dogmático a respeito dos contornos de uma obrigação geral de punir em direito internacional, ver Mark FreEman e MAX PENSKy. "The amnesty controversy in international law", em em LeIGH A. PAYNE e FranceSCA LESSA (eds.). Amnesty in the age of Human Rights Accountability, Cambridge, Cambridge University Press, 2012, p. 89-118. Segundo os autores: "In brief, the status of amnesty under international law is truly unsettled" (p. 112). 
Esta Corte considera que son inadmisibles las disposiciones de amnistía, las disposiciones de prescripción y el establecimiento de excluyentes de responsabilidad que pretendan impedir la investigación y sanción de los responsables de las violaciones graves de los derechos humanos tales como la tortura, las ejecuciones sumarias, extralegales o arbitrarias y las desapariciones forzadas, todas ellas prohibidas por contravenir derechos inderogables reconocidos por el Derecho Internacional de los Derechos Humanos. [...]

Las leyes de autoamnistía conducen a la indefensión de las víctimas y a la perpetuación de la impunidad, por lo que son manifiestamente incompatibles con la letra y el espíritu de la Convención Americana. este tipo de leyes impide la identificación de los individuos responsables de violaciones a derechos humanos, ya que se obstaculiza la investigación y el acceso a la justicia e impide a las víctimas y a sus familiares conocer la verdad y recibir la reparación correspondiente ${ }^{28}$.

Com foco nos direitos das vítimas de saber a verdade sobre violações, de acesso à justiça e reparações, a corte estabelece como aspecto mais importante em contextos de mudança de regime as violações de direitos humanos cometidas, de forma que a persecução criminal torna-se um equivalente direito para a ideia de justiça. Sem determinar a realização de julgamentos de perpetradores de direitos humanos, o Estado-parte na convenção deve ser responsabilizado internacionalmente perante o Sistema Interamericano de Direitos Humanos. Como já referido, esse discurso universalista de direitos humanos desenvolvido pela Corte Interamericana, nos termos do "critério interamericano sobre anistias", está compreendido no contexto da chamada luta contra impunidade em direito internacional.

A corte, ao estabelecer de maneira irredutível a ilicitude de anistias domésticas perante o direito internacional, obscurece os aspectos positivos que

28 Corte Interamericana, Barrios Altos, 2001a, cit., p. 15. Vale ressaltar que o caso salvadorenho El Mozote parece iniciar um movimento de revisão do "critério interamericano sobre anistias", propondo uma nova compreensão dos processos de justiça de transição latinoamericanos por parte da CIDH. A decisão da corte no caso El Mozote compartilha praticamente todos os pressupostos da jurisprudência interamericana sobre anistias, tendo sido afirmada a incompatibilidade entre a anistia salvadorenha ("Lei de Anistia Geral para a Consolidação da Paz") e o Pacto de San José da Costa Rica, tal como feito pela corte em Barrios Altos, Almonacid, Gomes Lund e Gelman. No entanto, a CIDH reconhece as especificidades de um conflito interno armado, justamente o contexto salvadorenho, o que fez com que a corte levasse em conta dispositivos dos direito internacional humanitário para chegar à sua decisão pela invalidação da anistia salvadorenha. Essa linha argumentativa parece ter aberto a possibilidade para a construção de novos entendimentos pela corte a respeito de processos transicionais latino-americanos. Tal empreitada me parece iniciada pelo Juiz Diego Garcia-Sayán em seu voto concorrente em El Mozote. O impacto do caso salvadorenho não será analisado nesta sede, pois escapa aos objetivos deste artigo. 
podem ser apontados relativamente a esse mecanismo de justiça transicional. O ponto aqui guarda estreita relação com o entendimento de 1985 sobre anistias: essas também podem se configurar como um instrumento de proteção aos direitos humanos. A priori, o direito internacional não determinaria de forma objetiva a licitude ou ilicitude desse mecanismo. Em outras palavras, faz-se necessário atentar ao "outro lado da moeda" do critério interamericano sobre anistias: os aspectos positivos desse mecanismo de justiça transicional.

Primeiramente, pode ser mencionada a estreita relação entre anistias e o contexto interno de transição política, já que processos de adoção desse benefício levam em consideração as limitações relacionadas às batalhas políticas e as considerações de caráter pragmático a respeito do que será necessário fazer (ou deixar de fazer) para possibilitar a mudança de regime. Contrariamente ao legalismo e ao formalismo de julgamentos, anistias lidam com as nuances políticas do processo interno de transformação de regime, sendo sensíveis para tal.

Assim, sem buscar afirmar a existência de um mundo de direitos humanos que exista para além da dimensão política, como se fosse possível organizar a realidade de modo a acabar com a "inconveniente" existência dessa dimensão ${ }^{29}$, anistias propiciam a retomada de questões políticas enquanto elemento fundamental para lidar com situações de mudança de regime.

Além da sensibilidade para o contexto local, a ausência de julgamentos permite que os Estados busquem superar seus conflitos internos de forma mais flexível. Sem a determinação de um estrito duty to punish, os Estados teriam mais espaço para modelar seus processos de transformação política. A questão da flexibilidade pressupõe a compreensão de que as ações que devem ser empreendidas para propiciar a transformação política não estariam objetivamente definidas. Assim, não haveria uma receita prévia ou predeterminada para iniciar e consolidar um processo de mudança de regime.

Aqui se faz interessante mencionar brevemente as discussões teóricas a respeito das possibilidades de forçar a abertura dos regimes autoritários latino-americanos no século passado. Como relata Paige Arthur $^{30}$, as origens do campo da justiça de transição estiveram relacionadas a uma ideia de reforma política em vez de transformação social. Assim, debates teóricos a respeito de explicações estruturalistas, como a teoria da modernização socioeconômica, foram revistos. Essa modernização deixaria de ser condição necessária para um processo de desenvolvimento político, sendo afirmada a possibilidade

29 JAN KLABBERS. Redemption song? Human rights versus community-building in East Timor, Leiden Journal of International Law, Leiden, v. 16, n. ${ }^{\circ}$ 2, 2003, p. 374.

30 PAIGE ARThUR. How "transitions" reshaped human rights: a conceptual history of transitional justice, Human Rights Quarterly, Baltimore, v. 31, n. 2 2, 2009, p. 334-348. 
de escolhas estratégicas por parte de uma elite política para possibilitar um processo de mudança de caráter político ${ }^{31}$.

Nesse contexto, um grupo de estudiosos latino-americanos - incluindo Fernando Henrique Cardoso e Guillermo O'Donnel -, entre outras nacionalidades, se reuniu no final dos anos 1970, sob os auspícios do Latin American Program, desenvolvido pelo Woodrow Wilson Center for Scholars, para pensar em que medida seria possível identificar oportunidades políticas para forçar a abertura das ditaduras na região ${ }^{32}$.

Paige Arthur não menciona se as anistias tiveram algum papel específico discutido nesse projeto do Woodrow Wilson Center, mas o que se pretende iluminar com essas breves considerações a respeito de tal movimentação de intelectuais latino-americanos é que a mudança de regime na região foi objeto de reflexões específicas e conscientes a respeito de seus possíveis contornos ${ }^{33}$.

Uma perspectiva de direitos humanos enquanto duty to prosecute coloca essa possibilidade de modelar processos de transformação política no escuro. As anistias, entendidas estritamente como violação de direitos internacional, passam a ser vistas como ato ilícito. No entanto, esse mecanismo não é necessariamente adotado ao acaso, como mero desvio. No caso da América Latina, a articulação de intelectuais que viam no protagonismo das elites políticas uma oportunidade factível para a abertura democrática na região esteve estreitamente relacionada ao processo de mudança de regime.

Não se trata de analisar, nesta tese, se tal estratégia de pacto das elites é errada ou correta, boa ou má, mas somente de ilustrar como processos de mudança de regime podem ser modelados pelas particularidades do caso concreto.

31 Paige Arthur, How transitions, cit., p. 338-339.

32 Papers foram produzidos por diversos cientistas políticos buscando identificar e debater tais oportunidades. Em setembro de 1979, FERNANDO HENRIQUE CARDOSO apresentou o seguinte trabalho CARDOSO, FERNANDO HENRIQUE. Os impasses do regime autoritário: o caso brasileiro, Estudos CEBRAP, São Paulo, v. 26, p. 170-194, 1980.

33 "Its [the project] key theme was that the origins of democracies are to be found in political choices rather than in structural conditions - and these choices are made by elites Drawing on the case studies they had commissioned for the project, O'DonNELL and SCHMITTER emphasized the inherent uncertainty of transitional outcomes, rejecting the contention that approaches applicable to stable periods were appropriate to transitional ones. They similarly placed enormous causal power in decisions taken, particularly by elites. They also emphasized the significance of bargaining on political outcomes, particularly in the form of pacts among elite groups. This latter point was one of the central elements of their argument. They divided the sequence of transitional 'moments' into a series of pacts, each of which would offer various interest groups mutual guarantees of protection - starting with the army, and working toward business and political elites. Though inherently undemocratic in terms of procedures, pacts are the best method of maintaining the stability necessary to establish a democracy, they concluded." Paige Arthur, How transitions, cit., p. 346. 
Deve-se mencionar também que anistias podem ser conjugadas a outros mecanismos de justiça de transição, como comissões de verdade e programas de reparação, o que torna viável um amplo leque de possibilidades para desenhar o processo de transformação política. A questão da busca pela verdade pode não ficar automaticamente marginalizada em processos de adoção de anistias. O procedimento de coleta de provas em um julgamento criminal não daria conta de incluir uma ampla narrativa histórica a respeito do regime anterior. As anistias, se adotadas em conjunto com uma comissão de verdade ou outras medidas de truth-telling, podem contribuir para a construção de relatos históricos, aptos inclusive a legitimar o novo regime, considerando de forma mais completa o caráter dual relativo à verdade, como já mencionado anteriormente neste capítulo.

Anistias conjugadas a mecanismos de truth-telling contemplam a questão política presente na situação de mudança de regime, escapando das limitações à obtenção da verdade decorrentes da produção de provas em procedimentos criminais. A realização de julgamentos enseja uma atuação estratégica dos indivíduos acusados no que tange à revelação dos fatos e à produção de provas, objetivando a inocência ou condenação com menor pena possível. Vale questionar se, diante de uma condenação provável, o acusado revelaria tudo o que sabe, com o risco de ser condenado com uma pena mais severa ante um relato integral do contexto fático e ausente qualquer programa de delação premiada.

Como outra virtude que pode ser mencionada, anistias possibilitam afirmar um debate a respeito do discurso de direitos humanos com contornos diversos, não enquanto discurso que seria tido como um bem em si, como o próprio objetivo a ser alcançado em termos de ideias relacionadas ao bem comum. Como afirma Jan Klabbers ${ }^{34}$, o discurso de direitos humanos pode ser visto enquanto garantia procedimental que facilita o embate político, sem generalizações, absolutismos ou universalismos ${ }^{35}$.

34 JAN KlABBERS. Redemption song?, cit., p. 374.

35 A posição relacionada à retomada da dimensão política pelo discurso de direitos humanos também é articulada por DAVID KENNEDY em capítulo de seu livro em que procura listar vários dark sides relacionados ao humanitarianism. Nesse sentido, uma pretensa neutralidade seria um lado obscuro a ser reconhecido. Como afirma o autor: "Neutral intervention. The human rights vocabulary promises Western constituencies a neutral and universalist mode of emancipatory intervention. This leads these constituencies to unwarranted innocence about the range of their other ongoing interventions and unwarranted faith in the benign natures of a human rights presence. Thinking their interventions being benign or neutral, they intervene more often than they otherwise might. Their interventions are less effective than they would be if pursued in other vocabularies." DAVID KENNEDY. The dark sides of virtue: Reassessing international humanitarianism, New Jersey, Princeton University, 2004, p. 23. Por seu turno, MarTti KosKenNiEM afirma que o caráter absolutista dos direitos humanos seria parte do próprio projeto liberal relacionado 
Assim, anistias possibilitam colocar luz em entendimentos diversos a respeito da proteção de direitos humanos, como discurso que permite a realização de debates e o estabelecimento de novos consensos políticos, de forma que tais direitos podem ser articulados de forma mais consciente, sem ilusões a respeito dos possíveis resultados a atingir. Em outras palavras, a obtenção de melhorias na realidade está relacionada a uma atuação política concreta, não somente à afirmação de direitos humanos em textos legais.

Nesse passo, o escopo de processos de transformação política não está dado de maneira objetiva. Cada situação de mudança de regime possui suas particularidades. As alternativas adequadas para lidar com cada um desses cenários particulares não podem ser estabelecidas a priori, com a exclusão da dimensão política do debate.

Por fim, uma das virtudes importantes relacionadas às anistias que deve ser mencionada neste trabalho é a questão da perspectiva das vítimas. Afinal, esse é o aspecto tido como positivo por aqueles que defendem um inequívoco duty to prosecute em direito internacional, ressaltando a impossibilidade de proteção dos direitos das vítimas em um contexto obscuro de impunidade obscuro no entendimento daqueles que preferem julgamentos.

Um primeiro aspecto da questão relacionada à perspectiva das vítimas é que a posição que afirma um duty to prosecute parece compreender as vítimas como uma unidade estanque e com interesses fixos no tempo e no espaço. As vítimas seriam, assim, um grupo homogêneo, que pensa sempre da mesma forma, independentemente dos contornos da situação real e da atuação estatal que pode ser empreendida para além de julgamentos.

Aliás, como afirma Louise Mallinder ${ }^{36}$, a própria identificação de quem é vítima em um contexto de mudança de regime pode ser um processo bastante complexo. Que tipo de sofrimento caracterizaria uma vítima? Ilustrativamente: as pessoas que foram torturadas por agentes estatais a serviços de esquemas de repressão política em ditaduras certamente podem ser consideradas vítimas. Essa mesma conclusão poderia ser apresentada para aqueles que sofreram ameaças de tortura, sem que fossem efetivamente torturados? O mesmo questionamento vale para aqueles que sofreram por conta da ansiedade e da perda de oportunidades na vida cotidiana em um contexto de conflito, sem

a esse discurso: "The absoluteness of rights discourse is not, however, an accidental property in it, but follows from its justifications within liberal theory, its purpose to create a set of unpolitical normative demands intended to 'trump' legislative policies or administrative discretion. The very point of rights as a special type of normative entitlements lies in their absoluteness, their uncontextual validity, and immediate applicability." MARTTI KOSKENNIEMI, "The effect of rights on political culture", em Koskenniemi, MARTti. The politics of international law, Oxford, Hart, 2011a, p. 149.

36 LOUISE MaLlinder. Amnesty, cit., p. 358-359. 
que tenham sofrido violações concretas de direitos humanos ou mesmo sem possuir familiares que tenham sofrido tais violações. Em outras palavras, o mero fato de viver sob um regime autoritário já caracterizaria a condição de vítima? Essas questões estão relacionadas a situações que, mais uma vez, não podem ser vistas de forma generalizante. A condição de vítima não está dada a priori $^{37}$.

Ademais, a perspectiva das vítimas muda com o passar do tempo e é afetada por fatores os mais diversos. O risco continuado de violência física, o bem-estar econômico, as tradições culturais da comunidade e as visões políticas desta ${ }^{38}$ são todos fatores que estão para além de uma escolha formal entre julgamentos ou anistias.

Anistias podem ser um instrumento interessante para dar conta dessa variabilidade de interesses, assumindo que decisões não são inalteráveis. Como referido, a possibilidade de associar anistias a outros mecanismos de justiça de transição é um aspecto positivo, na medida em que permite contemplar as alterações de um processo em curso. Condenações criminais, por sua vez, possuem efeitos mais fortes e rígidos, com regras e condições estritas para rever o resultado final de julgamentos.

Portanto, a adoção de anistias permite compreender a diversidade e variabilidade dos interesses dos envolvidos em um processo de mudança de regime sem que haja oposição forte entre vítimas e violadores, o que torna possível adaptar o desenho da justiça de transição às particularidades dos conflitos.

Finalmente, ainda no que tange à consideração dos direitos das vítimas, anistias possibilitam a reintegração à sociedade daqueles que lutaram contra o regime e que foram caracterizados como inimigos políticos das ditaduras, propiciando a restituição de direitos cassados, a volta de exilados e a revisão de condenações e procedimentos administrativos e judiciais de investigação.

Portanto, além das virtudes mencionadas nesta seção do texto - sensibilidade para o contexto local, flexibilidade, relacionamento mais abrangente com a verdade, perspectiva mais consciente do discurso de direitos humanos,

37 "In most countries, government institutions or transitional justice mechanisms have sought to identify, rather than applying the label to individuals who choose it for themselves. Nonetheless, an element of self-selection often remains, as victims decide whether to participate in any processes established by the government, although this choice can be restricted by conditioning reparations on participation. In most cases under consideration, states have created a legal definition of victimhood for the purposes of implementing transitional justice processes and awarding reparations. This can be problematic, however, as some countries have chosen to define the term narrowly. For example, the Argentine truth commission (CONADEP) only investigated cases of 'disappearance', and in Chile, the truth commission limited its findings to those human rights abuses resulting in death through torture, disappearance or execution." LOUISE MALLINDER. Amnesty, cit., p. 358.

38 Louise Mallinder. Amnesty, cit., p. 11. 
inclusão da dimensão política -, as anistias também consideram a perspectiva das vítimas, diferentemente do sustentado pela CIDH nos casos analisados no presente estudo.

A crítica que se busca construir à argumentação da corte em matéria de anistias está relacionada à perspectiva teórica de indeterminação do discurso de direitos humanos. Não haveria possibilidade de apontar preferências fixas contrárias às anistias e a favor de julgamentos, como faz a CIDH em suas decisões. As duas alternativas de justiça de transição têm aspectos positivos e negativos, perdas e ganhos que devem ser considerados para analisar sua possível adequação em contextos específicos de transformação política.

Assim, seguindo essa perspectiva teórica, para cada entendimento sobre uma regra jurídica, haveria um entendimento contrário possível ou uma exceção. Para cada princípio, um contraprincípio e para cada política institucional, um política em sentido oposto ${ }^{39}$. Ante o posicionamento da CIDH favorecendo julgamentos de violações e invalidando anistias, justificado por argumentos jurídicos plausíveis, também é possível articular um discurso a respeito das virtudes das anistias e dos problemas dos julgamentos, também com base em argumentos jurídicos plausíveis.

$\mathrm{O}$ discurso de direitos humanos permite essa diversidade argumentativa não apenas por uma questão de abertura semântica ${ }^{40}$, mas porque busca construir um espaço normativo de caráter apolítico, o qual seria oponível à atuação política dos Estados como arsenal capaz de proteger os detentores de direitos em relação a arbitrariedades estatais. O problema é que o significado dos direito humanos, seu alcance e seus limites não estão estabelecidos de forma inequívoca, mas dependem da maneira como são interpretados. Assim, direitos recebem significado na medida em que são relacionados a algum contexto ou propósito ${ }^{41}$.

Foi justamente a interpretação da Corte Interamericana que determinou um dever de julgar as violações vivenciadas no decorrer de regimes autoritários latino-americanos. Esse dever não está claramente estabelecido em tratados de direitos humanos, seja em âmbito regional, considerando o sistema interamericano, seja em âmbito global, considerando o sistema de proteção a esses direitos promovido pelas Nações Unidas.

Afirmar a indeterminação do discurso de direitos humanos não equivale a dizer que qualquer solução pode ser aceita, como se estivéssemos diante de

39 MARTTI KOSKENNIEMI. "International law and hegemony: a reconfiguration", em MARTTI KosKenNIEMI. The politics of international law, Oxford, Hart, 2011b, p. 223.

40 Koskenniemi, The effect of rights, cit., p. 147.

41 MartTi KoskenniEmi. "Human rights, politics and love", em em KosKenNiEMI, MarTti. The politics of international law, Oxford, Hart, 2011c, p. 158. 
práticas aleatórias ou lotéricas. O que se busca argumentar é que a adequação das alternativas hábeis para possibilitar processos pacíficos de mudança de regime não pode ser pensada por meio de critérios objetivos ou externos à prática. A utilidade de alternativas jurídicas só pode ser discutida levando em conta as escolhas políticas e morais empreendidas em cada uma das situações específicas de justiça de transição ${ }^{42}$.

Considerando o argumento da indeterminação, faz-se necessário compreender o que está em jogo em cada uma das alternativas que buscam articular a proteção de direitos humanos em contextos concretos de violações. Tais alternativas, como julgamentos e anistias, são equivalentes em princípio, isto é, as duas podem ser consideradas mecanismos importantes para propiciar uma mudança de regime pacífica. Uma escolha em favor de julgamentos ou em favor das anistias poderá ser feita de forma mais consistente se houver clareza a respeito das contingências do caso concreto e das limitações de um e outro mecanismo para lidar com ele. Sempre haverá problemas que não poderão ser resolvidos seja pela adoção de anistias, seja pela realização de julgamentos.

Afirmar a indeterminação do discurso de direitos humanos não corresponde à impossibilidade de decidir pela melhor maneira de realizar processos de mudança de regime, como uma atitude engessada em face das variadas possibilidades argumentativas proporcionadas por esse discurso. Decisões podem ser tomadas, e de fato o são, em diversos contextos transicionais.

O ponto fundamental a ser sublinhado é que tais decisões são motivadas por escolhas políticas, não se constituindo em manifestações neutras. $\mathrm{O}$ argumento da indeterminação permite compreender que as decisões são oriundas de pessoas e instituições reais. Assumir que existem possibilidades alternativas e que a escolha está disponível para todos aqueles envolvidos na prática argumentativa de direito internacional traz uma dimensão de responsabilidade para todos ${ }^{43}$. Embates políticos estão relacionados ao direito internacional e ao direito internacional dos direitos humanos, sendo necessário reconhecer os pressupostos de uma ação política que se apresenta por meio de argumentos jurídicos razoáveis e plausíveis.

\section{CONSIDERAÇÕES FINAIS}

O presente estudo teve como objetivo discutir o posicionamento específico da Corte Interamericana de Direitos Humanos relativamente à incompatibilidade

42 "Rights do not exist as such - 'fact-like' - outside the structures of political deliberation. They are not a limit, but an effect of politics." MARTTI KOSKENNIEMI. Human rights, politics and love, cit., p. 160.

43 David KenNEDy. The dark sides of virtue, cit., p. xxiv-xxvi. 
entre as anistias latino-americanas e os dispositivos da Convenção Americana de Direitos Humanos. Buscou-se chamar a atenção para as escolhas políticas relacionadas à argumentação da CIDH sobre a melhor maneira de lidar com contextos de violação e mudança de regime, afirmando não existirem manifestações neutras. No entanto, tais escolhas não foram expressamente declaradas pela corte, mas revestidas de um discurso universalista que trata os casos concretos enquanto violações de regras imperativas de direito internacional. Assim, seriam regras internacionais cogentes que determinariam um dever de julgamento, e não a atividade interpretativa da CIDH.

Parece inevitável reconhecer que a CIDH desenvolve tal posicionamento em benefício próprio, buscando garantir uma influência determinante na América Latina. Assim, sem uma análise mais aprofundada das contingências políticas dos casos concretos, foi afirmada a incompatibilidade das anistias locais com a convenção e a insuficiência dos processos de justiça de transição em países latino-americanos.

Esse discurso reduz a complexidade dos processos de justiça de transição ao excluir a sua dimensão política. Direitos humanos não estão em um ambiente neutro, para além da política, mas constituem-se em discurso que articula preferências a respeito da distribuição de bens materiais e espirituais no mundo, a respeito de certas ideias de bem comum. E essas preferências são articuladas por meio de argumentos jurídicos plausíveis, em virtude da indeterminação do discurso de direitos humanos.

Criticar a posição ideológica da corte em relação ao "critério interamericano sobre anistias" não possui como objetivo desconsiderar a importância da atuação de cortes internacionais de direitos humanos ou mesmo a relevância do discurso relacionado a esses direitos. Sem que seja necessário utilizar violência, traduzir pleitos para a linguagem de direitos permite que embates políticos se manifestem de forma mais pacífica, com base em regras estabelecidas coletivamente.

Ademais, este trabalho não buscou defender a posição de que toda e qualquer influência do direito internacional no direito interno deve ser afastada. No entanto, também não é possível afirmar que o mero fato de se constituir em corte de direitos humanos pressupõe que seja possível aceitar as manifestações da CIDH de maneira acrítica.

A Corte Interamericana, ao determinar de forma absolutista a realização de julgamentos e a incompatibilidade das anistias latino-americanas com a convenção, impede que os próprios interessados (no caso deste trabalho, as populações envolvidas) busquem reavaliar contextos políticos do passado de maneira responsável, assumindo as próprias escolhas no que tange aos variados contextos de mudança de regime na região. Uma instituição que impõe soluções, sem considerar o que se discute no âmbito local, atua de 
forma problemática, por mais que se constitua em uma corte internacional de direitos humanos. Não há razões na prática argumentativa do direito internacional que justifiquem aceitar uma superioridade natural da CIDH diante dos Estados-partes.

A atuação da corte nos casos debatidos neste trabalho parece ser facilitada pela posição distante que ela ocupa em relação às negociações e respectivas barganhas políticas dos processos latino-americanos de mudança de regime. Somente uma posição externa a esses processos pode ensejar manifestações tão unilaterais favorecendo julgamentos. Na medida em que a CIDH não precisa enfrentar os diversos interesses dos grupos que negociam uma possível transição pacífica, resta possível tratar dos casos de forma apolítica, como se a única questão a ser tratada fosse a caracterização das anistias como violações a regras internacionais de jus cogens.

No entanto, esse enquadramento dos casos constitui leitura parcial dos processos de transição política latino-americanos. E, como tal, é possível questionar se a abordagem universalista da CIDH seria capaz de "consertar" uma situação complexa de transformação política. Afinal, na medida em que anistias passam a ser vistas como ilícitos internacionais, seria necessário adequar o direito interno dos Estados-partes aos padrões supostamente superiores do sistema interamericano.

De uma maneira geral, a CIDH poderia atuar buscando um diálogo com a região e com as particularidades de cada país, assumindo suas posições de forma expressa. Assim, sem a intenção de dar a palavra final no que tange aos processos de transição política na região, a CIDH poderia contribuir para o debate público local oferecendo perspectivas diversas. É claro que tal atitude diminuiria substancialmente o poder da instituição na região em um primeiro momento, mas a corte poderia ter ganhos em médio e longo prazo, com um incremento do apoio dos Estados latino-americanos ao sistema interamericano.

Independentemente de qualquer sugestão de atuação para a corte, a análise empreendida neste trabalho buscou colocar luz na problemática de decisões que são parciais, mas que se definem como manifestações de caráter universal. Sem assumir as respectivas escolhas, a CIDH promete resolver todos os problemas relacionados a contextos de justiça de transição, sem considerar que em alguns casos não há certeza sobre a possibilidade de resolução via julgamentos, iludindo sua audiência a respeito dos pontos cegos de sua escolha e das virtudes de outras alternativas disponíveis.

Para além de uma mera desconstrução de um discurso de direitos humanos, este estudo teve como objetivo ressaltar a dimensão política que resta obscurecida pela corte ao desenvolver sua abordagem universalista. Considerar o que está em jogo na adoção de anistias ou na realização de julgamentos contribui para decisões mais consistentes em favor de uma ou de outra alternativa, tor- 
nando possível assumir a responsabilidade pelas escolhas efetuadas em um contexto repleto de controvérsias sobre a maneira adequada da concretizar uma transição política pacífica.

\section{REFERÊNCIAS BIBLIOGRÁFICAS}

ARTHUR, PAIGE. How "transitions" reshaped human rights: a conceptual history of transitional justice, Human Rights Quarterly, Baltimore, v. 31, n. ${ }^{\circ}$ 2, p. 321-367, 2009.

Bell, Christine. Transitional justice, interdisciplinarity and the state of the 'field' or 'nonfield', The International Journal of Transitional Justice, Oxford, v. 3, n. . 1, p. 5-27, 2009.

CARothers, Thomas. The end of the transition paradigm, Journal of Democracy, Washington, v. 13. n. ${ }^{\circ}$ 1, p. 5-21, 2002.

Freeman, Mark e Pensky, MaX. "The amnesty controversy in international law", em Leigh A. PAyne e Francesca LesSA (eds.). Amnesty in the age of Human Rights Accountability, Cambridge, Cambridge University Press, 2012, p. 89-118.

KENNEDY, DAVID. The dark sides of virtue: reassessing international humanitarianism, New Jersey, Princeton University, 2004.

KLABBERS, JAN. Redemption song? Human rights versus community-building in East Timor, Leiden Journal of International Law, Leiden, v. 16, n. ${ }^{\circ}$ 2, p. 367-376, 2003.

Koskenniemi, MARTti. “The effect of rights on political culture”, em MartTi KosKenniEmi. The politics of international law, Oxford, Hart, 2011a, p. 133-152.

Koskenniemi, MartTI. "International law and hegemony: a reconfiguration", em MartTi KoskenNiEmi. The politics of international law, Oxford, Hart, 2011b, p. 219-240.

Koskenniemi, Martti. "Human rights, politics and love", em Martti Koskenniemi. The politics of international law, Oxford, Hart, 2011c, p. 153-167.

KritZ, NeIL J. "The dilemmas of transitional justice", em NeIL J. KRITS (ed.). Transitional justice: how emerging democracies reckon with former regimes, Washington, United States Institute of Peace, 1995, v. 1. p. xix-xxx.

LeEbaw, Bronwyn AnNe. The irreconcilable goals of transitional justice, Human Rights Quarterly, Baltimore, v. 33, n.o 1, p. 95-118, 2008.

MALLINDER, LOUISE. Amnesty, human rights and political transitions: bridging the peace and justice divide, Oxford, Hart Publishing, 2008.

MALlinder, Louise. "Perspectivas transnacionais sobre anistias", em Leigh A. PAyne, PAulo AbraÃo, MARCElo D. Torelly (Orgs.). A anistia na era da responsabilização: o Brasil em perspectiva internacional e comparada, Brasília, Ministério da Justiça, Comissão de Anistia e Oxford, Oxford University Press, Latin American Centre, 2011, p. 473-505.

Olsen, Tricia D.; Payne, Leigh A.; ReIter, Andrew G. Transitional justice in balance: Comparing processes, weighing efficacy, Washington, United States Institute of Peace, 2010. 
OrentLicher, Diane F. Settling accounts: the duty to prosecute human rights violations of a prior regime, Yale Law Journal, New Haven, v. 100, n. . 8, p. 2537-2615, 1990-1991.

Payne, Leigh A., Lessa, Francesca. "Introduction”, em Leigh A. Payne e Francesca LesSA (eds.). Amnesty in the age of Human Rights Accountability, Cambridge, Cambridge University Press, 2012, p. 41-61.

Seibert-Fohr, Anja. Prosecuting serious human rights violations, Oxford, Oxford University Press, 2009.

Teitel, Ruti. Transitional justice genealogy, Harvard Human Rights Journal, Cambridge, v. 16, p. 69-94, 2003.

Teitel, Ruti. Transitional justice, New York, Oxford University Press, 2000.

Teitel, Ruti. Editorial note: Transitional justice globalized, The International Journal of Transitional Justice, Oxford, v. 2, n. ${ }^{\circ}$ 1, p. 1-4, 2008.

Comissão de Direitos Humanos das Nações Unidas, Subcomissão para Prevenção de Discriminação e Proteção de Minorias. The administration of justice and the human rights of detainees. Question of the Human Rights of Persons Subjected to Any Form of Detention or Imprisonment. Study on amnesty laws and their role in the safeguard and promotion of human rights. Preliminary report by Mr. Louis Joinet, Special Rapporteur (1985). Document E/CN.4/Sub.2/1985/16/Rev.1.,21st June 1985. Disponível em: <http://www1.umn. edu/humanrts/Amensty\%20Laws_Joinet.pdf>. Acesso em: 28 jul. 2015.

Corte Interamericana de Direitos Humanos. Caso Barrios Altos vs. Peru. Mérito. 14 mar. 2001a. Série C n. ${ }^{\circ}$ 75. Disponível em: <http://www.corteidh.or.cr/casos.cfm>. Acesso em: 28 jul. 2015.

Corte Interamericana de Direitos Humanos. Caso Barrios Altos vs. Peru. Interpretação da sentença de mérito. 3 set. 2001b. Série C n. ${ }^{\circ} 83$. Disponível em: <http://www.corteidh. or.cr/casos.cfm>. Acesso em: 28 jul. 2015.

Corte Interamericana de Direitos Humanos. Caso Barrios Altos vs. Peru. Reparações e custas. 30 nov. 2001c. Série C n. ${ }^{\circ}$ 87. Disponível em: <http://www.corteidh.or.cr/casos.cfm>. Acesso em: 28 jul. 2015.

Corte Interamericana de Direitos Humanos. Caso Almonacid-Arellano et al. vs. Chile. Exceções preliminares, mérito, reparações e custas, 26 set. 2006a. Série C n. ${ }^{\circ}$ 154. Disponível em: $<$ http://www.corteidh.or.cr/casos.cfm>. Acesso em: 28 jul. 2015.

Corte Interamericana de Direitos Humanos. Caso La Cantuta vs. Peru. Mérito, reparações e custas. 29 nov. 2006b. Série C n. ${ }^{\circ}$ 162. Disponível em: <http://www.corteidh.or.cr/casos. cfm>. Acesso em: 28 jul. 2015.

Corte Interamericana de Direitos Humanos. Caso Gomes Lund et al.(Guerrilha do Araguaia) vs. Brasil. Exceções preliminares, mérito, reparações e custas. 24 nov. 2010. Série C n. ${ }^{\circ}$ 219. Disponível em: <http://www.corteidh.or.cr/casos.cfm>. Acesso em: 28 jul. 2015. 
Corte Interamericana de Direitos Humanos. Caso Gelman vs. Uruguai. Mérito e reparações. 24 fev. 2011. Série C n.o 221. Disponível em: <http://www.corteidh.or.cr/casos.cfm>. Acesso em: 28 jul. 2015.

Corte Interamericana de Direitos Humanos. Caso Massacres de El Mozote e lugares adjacentes vs. El Salvador. Mérito, Reparações e Custas. 25 out. 2012. Série C n. 252. Disponível em: <http://www.corteidh.or.cr/casos.cfm>. Acesso em: 28 jul. 2015. 